\title{
Late-term results of tissue-engineered vascular grafts in humans
}

\author{
Narutoshi Hibino, MD, PhD, ${ }^{\text {a }}$ Edward McGillicuddy, MD, ${ }^{\text {a }}$ Goki Matsumura, MD, PhD, ${ }^{\text {b }}$ \\ Yuki Ichihara, MD, ${ }^{\mathrm{b}}$ Yuji Naito, MD, PhD, ${ }^{\mathrm{a}}$ Christopher Breuer, $\mathrm{MD},{ }^{\mathrm{a}}$ and Toshiharu Shinoka, MD, $\mathrm{PhD}{ }^{\mathrm{a}}$
}

Objective: The development of a tissue-engineered vascular graft with the ability to grow and remodel holds promise for advancing cardiac surgery. In 2001, we began a human trial evaluating these grafts in patients with single ventricle physiology. We report the late clinical and radiologic surveillance of a patient cohort that underwent implantation of tissue-engineered vascular grafts as extracardiac cavopulmonary conduits.

\begin{abstract}
Methods: Autologous bone marrow was obtained and the mononuclear cell component was collected. Mononuclear cells were seeded onto a biodegradable scaffold composed of polyglycolic acid and $\epsilon$-caprolactone/L-lactide and implanted as extracardiac cavopulmonary conduits in patients with single ventricle physiology. Patients were followed up by postoperative clinic visits and by telephone. Additionally, ultrasonography, angiography, computed tomography, and magnetic resonance imaging were used for postoperative graft surveillance.
\end{abstract}

Results: Twenty-five grafts were implanted (median patient age, 5.5 years). There was no graft-related mortality (mean follow-up, 5.8 years). There was no evidence of aneurysm formation, graft rupture, graft infection, or ectopic calcification. One patient had a partial mural thrombosis that was successfully treated with warfarin. Four patients had graft stenosis and underwent successful percutaneous angioplasty.

Conclusion: Tissue-engineered vascular grafts can be used as conduits in patients with single ventricle physiology. Graft stenosis is the primary mode of graft failure. Further follow-up and investigation for the mechanism of stenosis are warranted. (J Thorac Cardiovasc Surg 2010;139:431-6)

Supplemental material is available online.

Approximately $1 \%$ of all live births are affected by congenital heart disease, and each year approximately 10,000 children undergo reconstructive operations to repair complex congenital abnormalities. ${ }^{1}$ Currently used prosthetic materials, such as polytetrafluoroethylene, lack growth potential and are prone to thrombosis and infection. Additionally, prosthetic materials are nonviable and do not possess the ability to grow.

Through tissue engineering, it is feasible to construct a vascular graft that has structural and biochemical characteristics similar to those of a native vessel. ${ }^{2}$ By use of the classic tissue-engineering paradigm, an individual's own

From Yale University School of Medicine, ${ }^{\text {a }}$ Section of Cardiac Surgery, New Haven, Conn; and Tokyo Women's Medical University, ${ }^{\mathrm{b}}$ Tokyo, Japan.

Disclosures: R. Shinoka and C. Breur report grant support from Gunze, Ltd, the manufacturer of the scaffold used in this study.

Funded by the Doris Duke Charitable Foundation.

Read at the Eighty-ninth Annual Meeting of The American Association for Thoracic Surgery, Boston, Mass, May 9-13, 2009.

Received for publication April 30, 2009; revisions received Sept 14, 2009; accepted for publication Sept 29, 2009.

Address for reprints: Narutoshi Hibino, MD, PhD, Yale School of Medicine, Section of Cardiac Surgery, 333 Cedar St, Boardman 204, PO Box 208039, New Haven, CT 06520 (E-mail: narutoshi.hibino@yale.edu).

0022-5223/\$36.00

Published by Elsevier Inc. on behalf of The American Association for Thoracic Surgery doi:10.1016/j.jtcvs.2009.09.057 cells can be seeded onto a biodegradable scaffold, with the scaffold providing a source of cell attachment and early structural integrity. ${ }^{3}$ As the scaffold degrades, vascular neotissue forms and a living, biocompatible conduit is created.

$\mathrm{We}^{4}$ have previously reported the satisfactory short-term results of a human trial in which tissue-engineered vascular grafts (TEVGs) were implanted as extracardiac total cavopulmonary connections (TCPCs) in 25 patients with single ventricle physiology. In this study, we report the long-term clinical and radiologic surveillance of the patient cohort that underwent implantation of TEVGs as extracardiac TCPCs. Several imaging modalities, including angiography, computed tomography (CT), magnetic resonance imaging (MRI) angiography, and transthoracic ultrasonography, were used to assess TEVG patency and morphology.

\section{MATERIAL AND METHODS Scaffold Fabrication}

A hybrid tubular scaffold composed of a woven fabric of polyglycolic acid and $\epsilon$-caprolactone or L-lactide was constructed as previously described. ${ }^{4}$ On the basis of vessel size and hemodynamics, the appropriate diameter scaffold was selected (range, 12-24 mm). The scaffolds were 0.6 to $0.7 \mathrm{~mm}$ in thickness and $13 \mathrm{~cm}$ in length. The length of the scaffold was modified by the surgical team as necessary to accommodate each patient's anatomy.

\section{Cell Collection and Scaffold Preparation}

As described previously, ${ }^{4}$ with the patient under general anesthesia and before median sternotomy for the definitive operation, bone marrow $(5 \mathrm{~mL} /$ $\mathrm{kg}$ body weight) was aspirated from the anterosuperior iliac spine. The mononuclear cell component of the marrow $(2.26 \pm 1.02 \times 108$ cells $)$ 


\section{Abbreviations and Acronyms \\ $\mathrm{CT}=$ computed tomography \\ MRI = magnetic resonance imaging \\ $\mathrm{TCPC}=$ total cavopulmonary connection \\ $\mathrm{TEVG}=$ tissue-engineered vascular graft}

was collected with Histopaque-1077 (Sigma Chemical Co, St Louis, Mo) centrifugation, and these cells were seeded onto the scaffold by manual pipetting. The seeded scaffold was incubated in diluted autologous plasma for 2 hours before implantation.

\section{Surgical Implantation}

In 2001, the ethics committee at Tokyo Women's Medical University approved the implantation of TEVGs in human subjects. The following inclusion criteria were used for patient screening: elective surgery, age younger than 30 years, full understanding of the procedure by the patient or family, and minimal extracardiac disease burden. Informed consent was obtained from each patient, or from the parent/guardian if the patient was a minor, before proceeding. Between September 2001 and December 2004, 25 patients underwent an extracardiac TCPC using a TEVG (Table E1). The median patient age at the time of TEVG implantation was 5.5 years (range 1-24 years). The mean patient body weight at the time of TEVG implantation was $19.5 \mathrm{~kg}$ (range $7.5-51.6 \mathrm{~kg}$ ). The patients who had small grafts (patients 17 and 19) had an azygos connection. Anticoagulation therapy with warfarin sodium and aspirin was started 2 days postoperatively and continued for 3 to 6 months. Patients were monitored radiographically with transthoracic echocardiography, multislice CT, cineangiography, or MRI angiography. Patients were followed up postoperatively in a multidisciplinary clinic. Additionally, all patients were contacted by telephone to confirm their most recent clinical status.

\section{RESULTS}

\section{Early Trial Results}

We defined early results as clinical and radiographic events within 30 days of patient discharge after TEVG implantation. At this point, all patients were alive and free of symptoms. Postoperative angiography, ultrasonography, or CT demonstrated that all TEVGs were patent and there was no evidence of stenosis, thrombosis, or aneurysmal dilation of the TEVG.

\section{Trial Results 1 Year After Implantation}

Patients continued to be monitored with angiography, ultrasonography, MRI angiography, or CT (Figure E1). Partial mural thrombosis in 1 patient was successfully treated with warfarin anticoagulation (Figure E2). A patient with hypoplastic left heart syndrome died 6 months after TEVG implantation of congestive heart failure resulting from severe triscuspid regurgitation (Table 1).

\section{Most Recent Follow-up}

There was no graft-related mortality during the follow-up period (range, 4.3-7.3 years; mean, 5.8 years). All patients underwent a catheterization-based angiographic study, CT, or MRI. There was no evidence of aneurysm formation, graft rupture, or ectopic calcification in any graft interrogated with any imaging modality (Figure 1). Of note, 1 patient had a hemiazygous connection, and a 12-mm diameter TEVG was implanted; this graft was patent as demonstrated by postoperative imaging. In addition to the patient noted above in the 1-year analysis, 3 other patients died after TEVG implantation: A patient with tricuspid atresia died of complications related to subarachnoid hemorrhage 4 years after TEVG implantation; a second patient, with a known coronary artery anomaly diagnosed on cardiac catheterization, died suddenly 4 years postoperatively; a third patient, who had subaortic stenosis, died suddenly 2 years after graft implantation. Significantly, surveillance imaging in the months before all 4 patient deaths (including the patient who died during the midterm analysis) demonstrated a patent TEVG. Six (24\%) patients had asymptomatic graft narrowing noted on routine surveillance imaging. Four of 6 patients underwent successful balloon angioplasty (Figure 2), including 1 patient who required repeat balloon angioplasty and stent placement in the stenosed segment of the TEVG (Table 2).

\section{Postoperative Functional Status}

Surviving subjects were contacted by telephone in January 2009 to determine their current functional status. All contacted patients were attending school or work regularly. Seventeen $(81 \%)$ patients were in New York Heart Association functional class I and 3 patients were in functional class II. Eight patients (40\%) were not receiving any daily medications (Table 3).

\section{DISCUSSION}

Inasmuch as the prosthetic material used as conduits in surgery for congenital heart disease lacks growth potential, surgical reintervention is often necessary. 5,6 Additionally, synthetic grafts are at risk for thrombosis or infection. In an effort to overcome these limitations, we have applied tissue-engineering technology to the field of cardiac surgery. On the basis of several initial animal experiments, ${ }^{2,7-10}$ we have previously reported the successful implantation of TEVGs in humans (average follow-up, 1.3 years). In an effort to better characterize graft morbidity and mortality, we continued to monitor our surgical population clinically and radiographically. Our mean follow-up is now 5.8 years, and to this point no graft-related deaths have occurred. In a patient population that often has severe cardiovascular compromise, with a concomitantly shortened life expectancy, our data suggest that TEVGs are technically feasible.

One of the chief advantages of tissue engineering is the potential to create autologous tissue, obviating the need for antiplatelet, anticoagulant, or immunosuppressive therapy. In this study, anticoagulation and antiplatelet agents were 
TABLE 1. Patient status 1 year after TEVG implantation

\begin{tabular}{|c|c|c|c|c|c|c|c|}
\hline Patient & Age at operation (y) & Graft type & Graft size $(\mathrm{cm})$ & Patient status & Graft status & Graft patency & Graft-related complications \\
\hline 1 & 2 & PLA & 16 & Alive & Intact & Patent & None \\
\hline 2 & 1 & PLA & 20 & Alive & Intact & Patent & None \\
\hline 3 & 7 & PLA 1 & 8 & Alive & Intact & Patent & None \\
\hline 4 & 21 & PLA & 24 & Alive & Intact & Patent & None \\
\hline 5 & 4 & PLA & 20 & Alive & Intact & Patent & None \\
\hline 6 & 12 & PLA & 24 & Alive & Intact & Patent & None \\
\hline 7 & 17 & PLA & 24 & Alive & Intact & Patent & None \\
\hline 8 & 19 & PLA & 22 & Alive & Intact & Patent & None \\
\hline 9 & 3 & PLA & 12 & Alive & Intact & Patent & None \\
\hline 10 & 2 & PLA & 16 & Dead & Intact & Patent & None \\
\hline 11 & 2 & PGA & 16 & Alive & Intact & Patent & None \\
\hline 12 & 13 & PLA & 20 & Alive & Intact & Patent & None \\
\hline 13 & 2 & PGA & 16 & Alive & Intact & Patent & Thrombosis \\
\hline 14 & 2 & PGA & 18 & Alive & Intact & Patent & None \\
\hline 15 & 2 & PGA & 12 & Alive & Intact & Patent & None \\
\hline 16 & 2 & PGA & 16 & Alive & Intact & Patent & None \\
\hline 17 & 24 & PGA & 18 & Alive & Intact & Patent & None \\
\hline 18 & 1 & PGA & 16 & Alive & Intact & Patent & None \\
\hline 19 & 11 & PGA & 18 & Alive & Intact & Patent & None \\
\hline 20 & 2 & PGA & 16 & Alive & Intact & Patent & None \\
\hline 21 & 3 & PGA & 16 & Alive & Intact & Patent & None \\
\hline 22 & 4 & PGA & 18 & Alive & Intact & Patent & None \\
\hline 23 & 4 & PGA & 18 & Alive & Intact & Patent & None \\
\hline 24 & 13 & PGA & 16 & Alive & Intact & Patent & None \\
\hline 25 & 2 & PGA & 18 & Alive & Intact & Patent & None \\
\hline
\end{tabular}

$T E V G$, Tissue-engineered vascular graft; $P L A$, poly-L-lactic acid; $P G A$, Polyglycolic acid.

discontinued 6 months postoperatively in all patients with no evidence of graft thrombosis ( $96 \%$ ). In the long term, $40 \%$ of patients remained free of any daily medications, which improves quality of life and decreases the incidence of medication-related complications and comorbidities. In contrast, in studies investigating artificial graft materials such as Dacron or polytetrafluoroethylene, most subjects received long-term oral anticoagulation with warfarin or antiplatelet therapy with aspirin. ${ }^{11-13}$

The remodeling of TEVGs and the mechanisms of vascular neotissue formation remain a most compelling and intensely studied subject. In this study, surveillance imaging revealed graft stenoses in $6(24 \%)$ patients. This stenosis rate was greater than in those studies investigating artificial graft material. ${ }^{11-13}$ Graft stenosis, however, is frequently asymptomatic, leading to significant underreporting. ${ }^{14}$ When serially imaged with MRI, all synthetic grafts have some degree of stenosis within 6 months of implantation, with a mean $18 \%$ reduction in diameter and a maximum reduction of $32 \% .{ }^{11}$ These finding were confirmed in a second study evaluating extracardiac TCPC graft morphology using angiography. ${ }^{15}$ Graft narrowing tended to stabilize after this
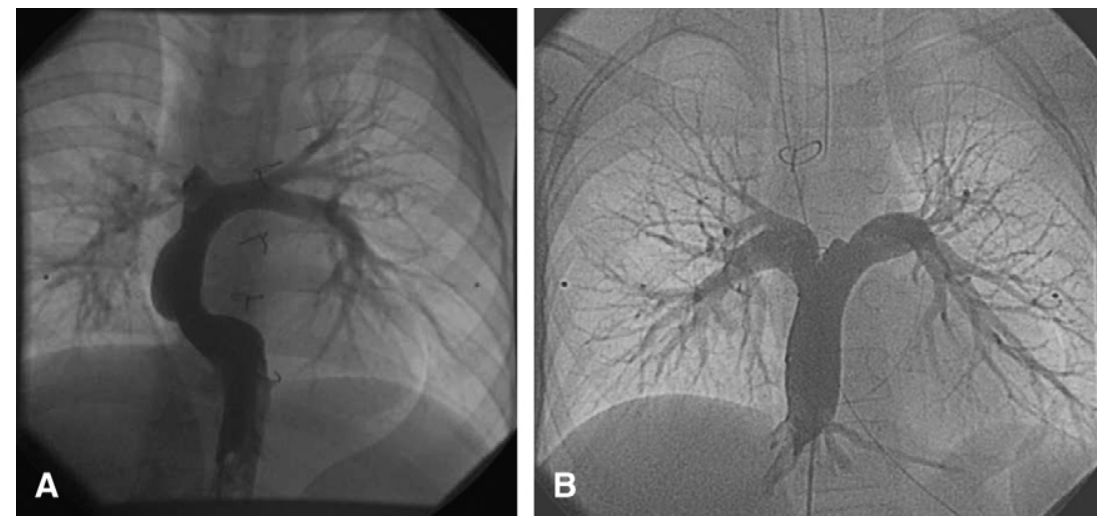

FIGURE 1. TEVG angiography, 5 years after implantation (A) and 4 years after implantation (B). There was no stenosis, aneurysm formation, or ectopic calcification in these TEVGs. 

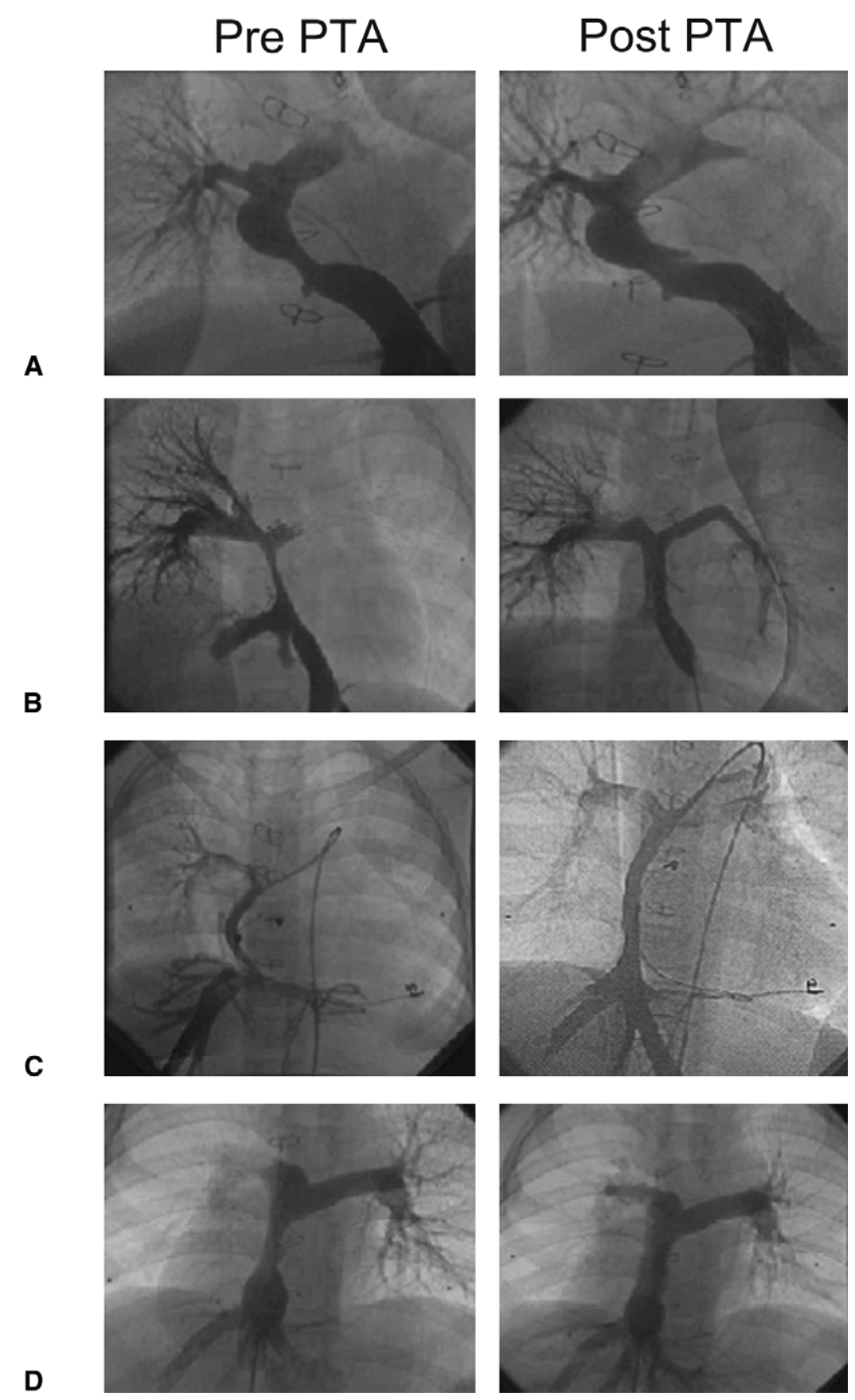

FIGURE 2. Four patients (A-D) with TEVG stenosis underwent successful balloon angioplasty. PTA, Percutaneous transluminal angioplasty.

initial period, but the use of angioplasty and stenting is described in many series. ${ }^{11,16}$ Additionally, the degree of stenosis is difficult to estimate based on a variety of variables, including the change of shape of a conduit from a circular cross section to an oval cross section that often occurs. Also, the 3-dimensional nature of vascular grafts limits accurate size and boundary detection with 2-dimensional modalities such as angiography. ${ }^{15}$ Finally, indications for the therapy of asymptomatic stenosis are not standardized, leading to significant variability in the use of angioplasty, stenting, and graft replacement.

The limitations of this study must be acknowledged. Although this trial represents the first use of tissue-engineered conduits in humans, the number of study subjects was relatively small and only a single institution was involved. Furthermore, a standard radiologic surveillance protocol was not adhered to. Finally, this study was not randomized with matched controls. Currently, we are applying to the 
TABLE 2. Patient late-term status after TEVG implantation

\begin{tabular}{|c|c|c|c|c|c|c|c|}
\hline Patient & Age at operation & Graft type & Graft size $(\mathrm{cm})$ & Patient status & Graft status & Graft patency & Graft-related complications \\
\hline 1 & 2 & PLA & 16 & Alive & Intact & Patent & None \\
\hline 2 & 1 & PLA & 20 & Alive & Intact & Patent & None \\
\hline 3 & 7 & PLA & 18 & Alive & Intact & Patent & Stenosis* \\
\hline 4 & 21 & PLA & 24 & Alive & Intact & Patent & None \\
\hline 5 & 4 & PLA & 20 & Alive & Intact & Patent & None \\
\hline 6 & 12 & PLA & 24 & Alive & Intact & Patent & None \\
\hline 7 & 17 & PLA & 24 & Alive & Intact & Patent & None \\
\hline 8 & 19 & PLA & 22 & Dead & Intact & Patent & None \\
\hline 9 & 3 & PLA & 12 & Alive & Intact & Patent & Stenosis* \\
\hline 10 & 2 & PLA & 16 & Dead & Intact & Patent & None \\
\hline 11 & 2 & PLA & 20 & Dead & Intact & Patent & None \\
\hline 12 & 13 & PGA & 16 & Alive & Intact & Patent & Stenosis* \\
\hline 13 & 2 & PGA & 16 & Alive & Intact & Patent & Thrombosis \\
\hline 14 & 2 & PGA & 18 & Alive & Intact & Patent & None \\
\hline 15 & 2 & PGA & 12 & Alive & Intact & Patent & None \\
\hline 16 & 2 & PGA & 16 & Alive & Intact & Patent & None \\
\hline 17 & 24 & PGA & 18 & Alive & Intact & Patent & None \\
\hline 18 & 1 & PGA & 16 & Alive & Intact & Patent & Stenosis* \\
\hline 19 & 11 & PGA & 18 & Alive & Intact & Patent & None \\
\hline 20 & 2 & PGA & 16 & Alive & Intact & Patent & None \\
\hline 21 & 3 & PGA & 16 & Alive & Intact & Patent & None \\
\hline 22 & 4 & PGA & 18 & Alive & Intact & Patent & None \\
\hline 23 & 4 & PGA & 18 & Alive & Intact & Patent & None \\
\hline 24 & 13 & PGA & 16 & Alive & Intact & Patent & None \\
\hline 25 & 2 & PGA & 18 & Dead & Intact & Patent & None \\
\hline
\end{tabular}

TEVG, Tissue-engineered vascular graft; $P L A$, poly-L-lactic acid; $P G A$, Polyglycolic acid. $*$ This patient underwent successful angioplasty.

TABLE 3. Summary of the results of TEVG telephone survey

\begin{tabular}{|c|c|c|c|c|c|c|}
\hline Patient & Telephone contact & Patient status & NYHA class & Attends school/(work) & $\begin{array}{c}\text { Participates in } \\
\text { gym/(atheletics) }\end{array}$ & $\begin{array}{c}\text { Reported body } \\
\text { weight (weight at surgery) }\end{array}$ \\
\hline 1 & Yes & Alive \& well & $\mathrm{I}$ & Yes & Yes & $27 \mathrm{~kg}(11 \mathrm{~kg})$ \\
\hline 2 & Yes & Alive \& well & $\mathrm{I}$ & Yes & Yes & $24 \mathrm{~kg}(8 \mathrm{~kg})$ \\
\hline 3 & Yes & Alive \& well & II & Yes & No & $23 \mathrm{~kg}(19 \mathrm{~kg})$ \\
\hline 4 & Yes & Alive \& well & $\mathrm{I}$ & Yes & Yes & $47 \mathrm{~kg}(44 \mathrm{~kg})$ \\
\hline 5 & Yes & Alive \& well & I & Yes & Yes & $32 \mathrm{~kg}(14 \mathrm{~kg})$ \\
\hline 6 & Yes & Alive \& well & $\mathrm{I}$ & Yes & Yes & $53 \mathrm{~kg}(37 \mathrm{~kg})$ \\
\hline 7 & Yes & Alive \& well & II & Yes & No & $54 \mathrm{~kg}(47 \mathrm{~kg})$ \\
\hline 8 & N/A & dead & N/A & N/A & N/A & N/A \\
\hline 9 & Yes & Alive \& well & $\mathrm{I}$ & Yes & Yes & $29 \mathrm{~kg}(14 \mathrm{~kg})$ \\
\hline 10 & N/A & dead & N/A & N/A & N/A & N/A \\
\hline 11 & Yes & Alive \& well & $\mathrm{I}$ & Yes & Yes & $24 \mathrm{~kg}(11 \mathrm{~kg})$ \\
\hline 12 & Yes & dead & $\mathrm{N} / \mathrm{A}$ & N/A & N/A & $\mathrm{N} / \mathrm{A}$ \\
\hline 13 & Yes & Alive \& well & $\mathrm{I}$ & Yes & Yes & $21 \mathrm{~kg}(10 \mathrm{~kg})$ \\
\hline 14 & Yes & Alive \& well & II & Yes & No & $22 \mathrm{~kg}(9 \mathrm{~kg})$ \\
\hline 15 & Yes & Alive \& well & $\mathrm{I}$ & Yes & Yes & $24 \mathrm{~kg}(11 \mathrm{~kg})$ \\
\hline 16 & Yes & Alive \& well & $\mathrm{I}$ & Yes & Yes & 19 kg (9 kg) \\
\hline 17 & Yes & Alive \& well & I & Yes & Yes & $55 \mathrm{~kg}(52 \mathrm{~kg})$ \\
\hline 18 & Yes & Alive \& well & $\mathrm{I}$ & Yes & Yes & $20 \mathrm{~kg}(9 \mathrm{~kg})$ \\
\hline 19 & Yes & Alive \& well & $\mathrm{I}$ & Yes & Yes & $54 \mathrm{~kg}(26 \mathrm{~kg})$ \\
\hline 20 & Yes & Alive \& well & $\mathrm{I}$ & Yes & Yes & $22 \mathrm{~kg}(11 \mathrm{~kg})$ \\
\hline 21 & Yes & Alive \& well & I & Yes & Yes & $15 \mathrm{~kg}(11 \mathrm{~kg})$ \\
\hline 22 & Yes & Alive \& well & $\mathrm{I}$ & Yes & Yes & $22 \mathrm{~kg}(13 \mathrm{~kg})$ \\
\hline 23 & No & N/A & N/A & N/A & N/A & N/A \\
\hline 24 & Yes & Alive \& well & $\mathrm{I}$ & Yes & Yes & $43 \mathrm{~kg}(26 \mathrm{~kg})$ \\
\hline 25 & No & Dead & N/A & N/A & N/A & N/A \\
\hline
\end{tabular}

TEVG, Tissue-engineered vascular graft; $N Y H A$, New York Heart Association; N/A, not available. 
United States Food and Drug Administration and our institutional review board for permission to implant TEVGs in humans with single ventricle physiology.

In conclusion, this trial demonstrates the feasibility of using tissue-engineering technology to create vascular grafts for use as extracardiac TCPCs. Inasmuch as stenosis is the primary mode of graft failure on TEVGs, further follow-up and investigation for the mechanism of stenosis are warranted. Continued study regarding the mechanisms of TEVG stenosis will allow us to generate the next generation of TEVGs.

\section{References}

1. Hoffman JI, Kaplan S. The incidence of congenital heart disease. J Am Coll Cardiol. 2002;39:1890-900.

2. Shinoka T, Shum-Tim D, Ma PX, Tanel RE, Isogai N, Langer R, et al. Creation of viable pulmonary artery autografts through tissue engineering. J Thorac Cardiovasc Surg. 1998;115:536-45; discussion 545-546.

3. Matsumura G, Miyagawa-Tomita S, Shin'oka T, Ikada Y, Kurosawa H. First evidence that bone marrow cells contribute to the construction of tissue-engineered vascular autografts in vivo. Circulation. 2003;108:1729-34.

4. Shin'oka T, Matsumura G, Hibino N, Naito Y, Watanabe M, Konuma T, et al. Midterm clinical result of tissue-engineered vascular autografts seeded with autologous bone marrow cells. J Thorac Cardiovasc Surg. 2005;129:1330-8.

5. Albert JD, Bishop DA, Fullerton DA, Campbell DN, Clarke DR. Conduit reconstruction of the right ventricular outflow tract. Lessons learned in a twelve-year experience. J Thorac Cardiovasc Surg. 1993;106:228-35; discussion 235-236.

6. Breymann T, Thies WR, Boethig D, Goerg R, Blanz U, Koerfer R. Bovine valved venous xenografts for RVOT reconstruction: results after 71 implantations. Eur J Cardiothorac Surg. 2002;21:703-10; discussion 710.

7. Shinoka T, Breuer CK, Tanel RE, Zund G, Miura T, Ma PX, et al. Tissue engineering heart valves: valve leaflet replacement study in a lamb model. Ann Thorac Surg. 1995;60:S513-6.

8. Shinoka T, Ma PX, Shum-Tim D, Breuer CK, Cusick RA, Zund G, et al. Tissueengineered heart valves. Autologous valve leaflet replacement study in a lamb model. Circulation. 1996;94(9 Suppl):II164-8.

9. Shinoka T, Shum-Tim D, Ma PX, et al. Tissue-engineered heart valve leaflets: does cell origin affect outcome? Circulation. 1997;96(9 Suppl). II-102-107.
10. Watanabe M, Shin'oka T, Tohyama S, Hibino N, Konuma T, Matsumura G, et al. Tissue-engineered vascular autograft: inferior vena cava replacement in a dog model. Tissue Eng. 2001;7:429-39.

11. Giannico S, Hammad F, Amodeo A, Michielon G, Drago F, Turchetta A, et al. Clinical outcome of 193 extracardiac Fontan patients: the first 15 years. $J$ Am Coll Cardiol. 2006;47:2065-73.

12. Kim SJ, Kim WH, Lim HG, Lee JY. Outcome of 200 patients after an extracardiac Fontan procedure. J Thorac Cardiovasc Surg. 2008;136:108-16.

13. Nakano T, Kado H, Tachibana T, Hinokiyama K, Shiose A, Kajimoto M, et al. Excellent midterm outcome of extracardiac conduit total cavopulmonary connection: results of 126 cases. Ann Thorac Surg. 2007;84:1619-25; discussion $1625-1626$.

14. Chowdhury UK, Airan B, Kothari SS, Talwar S, Saxena A, Singh R, et al. Specific issues after extracardiac Fontan operation: ventricular function, growth potential, arrhythmia, and thromboembolism. Ann Thorac Surg. 2005;80:665-72.

15. Lee C, Lee CH, Hwang SW, Lim HG, Kim SJ, Lee JY, et al. Midterm follow-up of the status of Gore-Tex graft after extracardiac conduit Fontan procedure. Eur J Cardiothorac Surg. 2007;31:1008-12.

16. Amodeo A, Galletti L, Marianeschi S, Picardo S, Giannico S, Di Renzi P, et al. Extracardiac Fontan operation for complex cardiac anomalies: seven years' experience. J Thorac Cardiovasc Surg. 1997;114:1020-30.

\section{Discussion}

Dr John Edmund Mayer, Jr (Boston, Mass). You have some patients who have not survived long term in your tissue-engineered extracardiac Fontan group. Do you have any histologic studies on those explanted grafts from autopsy?

Dr Hibino. Unfortunately, for these TCPC graft-implanted patients, the families declined autopsies; therefore, we do not have the histologic information. We have the histologic data, however, from reoperation patients. In these patients we used a tissue engineered graft as a patch for pulmonary angioplasty in a stenosed region. After the angioplasty, pulmonary artery stenosis developed again, including the portion replaced with the TEVG. Here is the histology of the explanted graft at reoperation. In this image we note endothelialization of the tissue and smooth muscle layer formation, which suggests neotissue formation. 


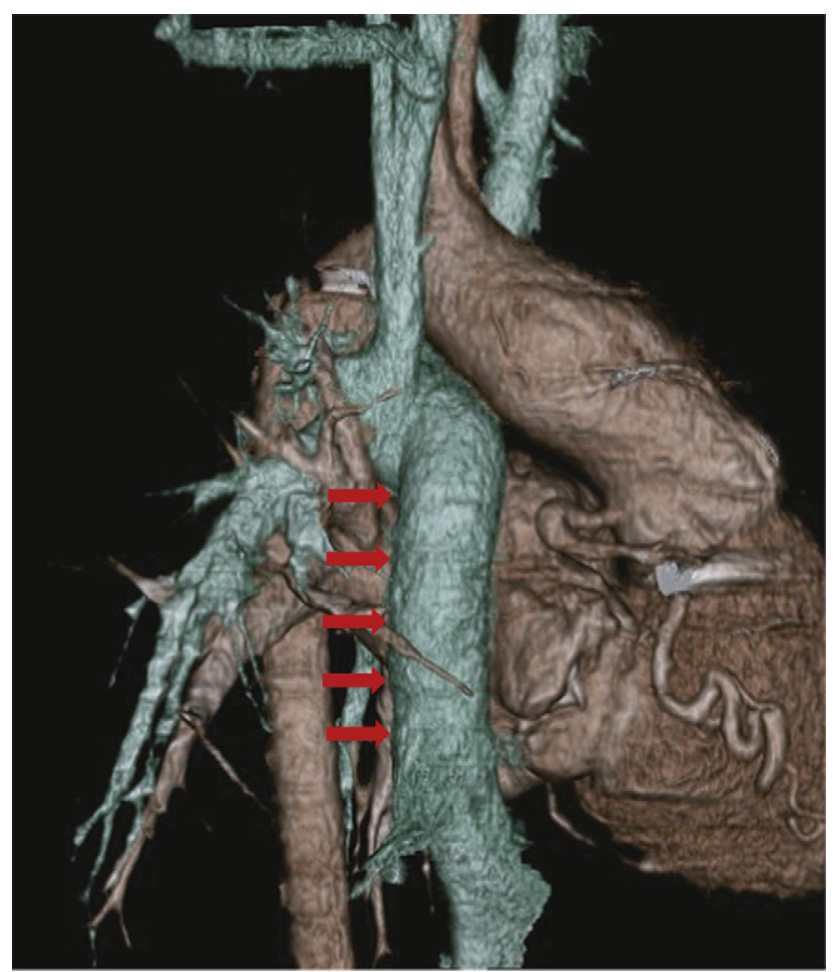

FIGURE E1. Three-dimensional CT 1 year after TEVG implantation. The graft is patent and there is no aneurysmal dilation. Arrows denote extracardiac TCPC graft.

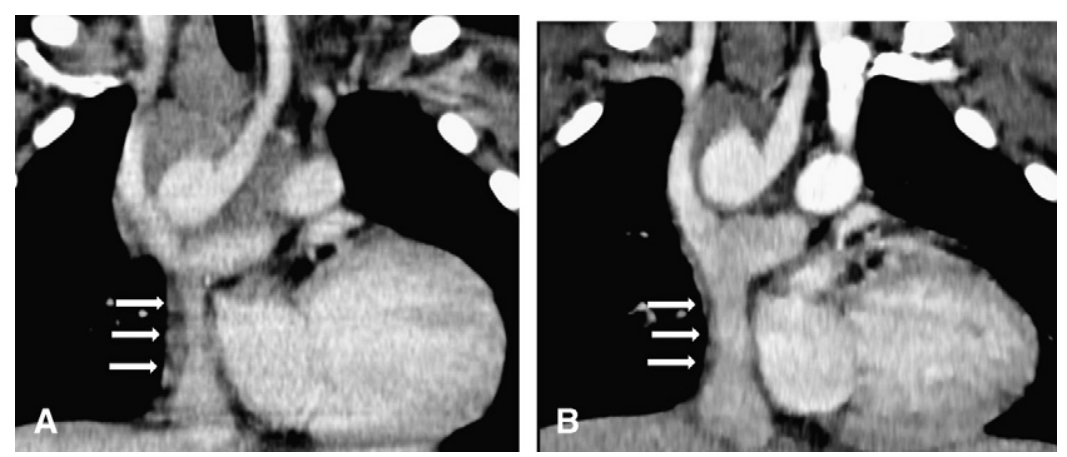

FIGURE E2. Partial mural thrombus 1 year after TEVG implantation (A, arrows) was successfully treated with warfarin anticoagulation (B, arrows). 
TABLE E1. Patient demographics, diagnoses, and graft type at the time of implantation

\begin{tabular}{|c|c|c|c|c|c|c|}
\hline Patient & Age (y) & Weight (kg) & Gender & TEVG (PGA/PLA) & Size $(\mathbf{m m})$ & Diagnosis \\
\hline 1 & 2 & 11 & M & PLA & 16 & Asplenia, AVSD (A), small RV \\
\hline 2 & 1 & 7 & M & PLA & 20 & Asplenia, SRV, DORV, TAPVC (Ib+III) \\
\hline 3 & 7 & 18 & $\mathrm{~F}$ & PLA & 18 & Concordant criss-cross heart, DORV, PAA, MS \\
\hline 4 & 21 & 44 & $\mathrm{~F}$ & PLA & 24 & TA (Ib) \\
\hline 5 & 4 & 14 & M & PLA & 20 & SRV, DORV, AVVA \\
\hline 6 & 12 & 36 & $\mathrm{~F}$ & PLA & 24 & Total sinus defect, ASD, TR (III) \\
\hline 7 & 17 & 46 & M & PLA & 24 & Aspenia, SLV, CAVVR (III) \\
\hline 8 & 19 & 47 & $\mathrm{~F}$ & PLA & 22 & TA (Ib) \\
\hline 9 & 3 & 13 & $\mathrm{~F}$ & PLA & 12 & Polyspenia, SRV \\
\hline 10 & 2 & 7 & $\mathrm{~F}$ & PLA & 16 & HLHS, MA, IAA (A) \\
\hline 11 & 2 & 11 & $\mathrm{~F}$ & PGA & 16 & Asplenia, SRV, PAA, nonconfluent PA \\
\hline 12 & 13 & 23 & $\mathrm{~F}$ & PLA & 20 & PPA, ASD (II), sinusoidal communication \\
\hline 13 & 2 & 9 & M & PGA & 16 & SLV, DILV, Lt AVVA \\
\hline 14 & 2 & 9 & $\mathrm{~F}$ & PGA & 18 & DORV, small LV, VSD, PS, ASD (II) \\
\hline 15 & 2 & 11 & $\mathrm{~F}$ & PGA & 12 & Polysplenia, cAVSD (A), DORV, PS, CAVVR \\
\hline 16 & 2 & 8 & $\mathrm{~F}$ & PGA & 16 & Asplenia, SRV, CAVV, CA, TAPVC (Ib), CAVVR (I) \\
\hline 17 & 24 & 51 & M & PGA & 18 & TA (Ia), RA giant thrombosis \\
\hline 18 & 1 & 8 & M & PGA & 16 & SRV, DIRV, PA, ASD (II) \\
\hline 19 & 11 & 25 & M & PGA & 18 & Asplenia, cAVSD, PS, CAVV, CAVVR (I) \\
\hline 20 & 2 & 11 & $\mathrm{~F}$ & PGA & 12 & Polysplenia, cAVSD, PS, CAVV, CAVVR (I) \\
\hline 21 & 3 & 10 & $\mathrm{~F}$ & PGA & 16 & DORV, VSD, small RA, PLSVC, TAPVC (IIb) \\
\hline 22 & 4 & 13 & M & PGA & 18 & PPA, ASD (II), PDA, sinusoidal communication \\
\hline 23 & 4 & 14 & $\mathrm{~F}$ & PGA & 18 & SLV, DILV, PAA, ASD, bilateral SVC \\
\hline 24 & 13 & 25 & $\mathrm{~F}$ & PGA & 16 & Asplenia, SRV \\
\hline 25 & 2 & 9 & M & PGA & 18 & TA, SAS \\
\hline
\end{tabular}

$T E V G$, Tissue-engineered vascular graft; $P G A$, Polyglycolic acid; $P L A$, poly-L-lactic acid; $A V S D$, atrioventricular septal defect; $R V$, right ventricle; $S R V$, single right ventricle; $D O R V$, double-outlet right ventricle; TAPVC, total anomalous pulmonary venous connection; PAA, pulmonary artery atresia; $M S$, mitral stenosis; TA, tricuspid atresia; $A V V A$, atrioventricular valve atresia; $A S D$, atrial septal defect; $T R$, tricuspid regurgitation; $S L V$, single left ventricle; $C A V V R$, common atrioventricular valve regurgitation; $S R V$, single right ventricle; $H L H S$, hypoplastic left heart syndrome; $M A$, mitral atresia; $I A A$, interruption of aortic arch; $P A$, pulmonary artery; $P P A$, pure pulmonary atresia; $D I L V$, double-inlet left ventricle; $L V$, left ventricle; $V S D$, ventricular septal defect; $P S$, pulmonary stenosis; $A S D$, atrial septal defect; $c A V S D$, complete atrioventricular septal defect; $C A V V$, common atrioventricular valve; $C A$, common atrium; $R A$, right atrium; $P L S V C$, persistent left superior vena cava; $P D A$, patent ductus arteriosus; $S V C$, superior vena cava; $S A S$, subaortic stenosis. 